\title{
Intercellular structure in a many-celled magnetotactic prokaryote
}

\author{
Frank G. Rodgers' ${ }^{1}$, Richard P. Blakemore', Nancy A. Blakemore', Richard B. Frankel ${ }^{2}$, Dennis A. Bazylinski *, \\ Denise Maratea * * and Christine Rodgers ${ }^{1}$ \\ ${ }^{1}$ Department of Microbiology, Spaulding Life Science Building, University of New Hampshire, Durham, NH 03824, USA \\ 2 Department of Physies, California Polytechnic State University, San Luis Obispo, CA 93407, USA
}

\begin{abstract}
A many-called magnetotactic prokaryote obtained from brackish water was observed to possess intercellular connections at points of contact between the outer membranes of constituent cells. Each aggregate organism consisted of 10 to 30 individual Gram-negative cells containing material with the appearance of poly- $\beta$ hydroxybutyrate and magnetosomes of unusual arrangement, structure and composition. The aggregate, which possessed prokaryotic-type flagella arranged at the outwards surfaces of each cell, showed motility indicative of co-ordination between individual component cells. Thesc results suggest that this organism could be a multicellular prokaryote.
\end{abstract}

Key words: Intercellular junctions - Multicellularity in prokaryotes - Bacterial magnetotaxis - Ultrastructure - Bacterial co-ordination

Magnetotactic bacteria orient and migrate along geomagnetic ficld lines (Blakemore 1975, 1982). Many morphologically diverse types inhabit freshwater and marine waters and sediments (Blakemore et al. 1989). An unusual magnetotactic micro-organism has been collected from sulphide-rich marine and brackish nearshore, pond, and lagoon waters and sediments of the east and west coasts of North America. The organism was a highly motile, highly refractile spherical cell aggregate or microcolony of prokaryotic cells that migrated as an intact unit in the geomagnetic field direction. A similar organism that migrated opposite to the geomagnetic field direction has been collected in Brazil (Farina et al, 1983). We rcport here on the structure of this many-celled organism. Ol particular interest is the observation that individual cells in the aggregate organism are connected to each other by outer mombranes that join together forming regions with the structural appearance of cell-to-cell junctions.

\begin{abstract}
Materials and methods
Organism collection. Glass jars filled with black mud or sand and water from marine and brackish coastal sites in New England with salinity yalues between 12 and 32 parts per thousand were stored loosely covered in dim light at room temperature $\left(25^{\circ} \mathrm{C}\right)$ and left undisturbed for several days. Rust-colored films at the air/water interface and the odor of $\mathrm{H}_{2} \mathrm{~S}$ were characteristic of these natural enrichments. At this time, $\mathrm{pH}$ values of the water were usually 7.3 at the surface and 6.5 near the botton where the magnetotactic bacteria were located. Total iron values in surface sediments, as measured by the ferrozine method (Stookey 1970), ranged from a low of 0.6 to as high as $28.7 \mathrm{mg}^{-1}$. In contrast to other types of magnetotactic bacteria, these aggregate organisms usually disappeared from the enrichments within three weeks, at which time large populations of photosynthetic green sulphur bacteria appeared. Suspensions of organisms for phase contrast and electron microscopy were harvested by applying a magnet to the outside of the jars (Moench and Konetrka 1978). Unlike other magnetotactic bacteria which aggregate in dense eell pellets, these many celled organisms localized in a loose cloud at the south magnetic pole.
\end{abstract}

Electron microscopy. Organsins in suspension were prepared for transmission electron microscopy by fixation in $3 \%(\mathrm{v} / \mathrm{v}) \mathrm{glu}-$ taraldehyde in $0.05 \mathrm{M}$ cacodylate buffer containing $10 \mathrm{mM}$ magnesium sulphate at $\mathrm{pH} 7.3$ (Rodgers and Davey 1982). The fixed suspensions were centrifuged and the pellets pre-embedded in $2 \%$ (w/v) agarose for further preparation for thin-section electron microscopy. Samples were post-fixed in $1 \%(\mathrm{w} / \mathrm{v}) \mathrm{OsO}_{4}$, dehydrated in a graded ethanol series and embedded in an Epon-araldite resin mixture. Thin-sections were cut on an LKB Ultratome III, stained with $5 \%$ (w/v) uranyl acetate for $60 \mathrm{~s}$ and $0.4 \%$ (w/v) lead citrate for $20 \mathrm{~s}$ (Rodgers 1979). Similar organism suspensions were applied to formvar-carbon-coated grids and negatively stained with $2.5^{\circ} \%$ (w/v) ammonium molybdate. Thin-sectioned and negatively stained material was examined in a Hitachi 1600 or Jeol 100 S electron microscope. For scanning electron microscopy, organisms werecritical point dried from $\mathrm{CO}_{2}$, sputter coated with gold and examined in an AMR 1000 scanning electron microscope. Thin-sections were also examined by energy dispersive X-ray analysis in a VG Micro- 

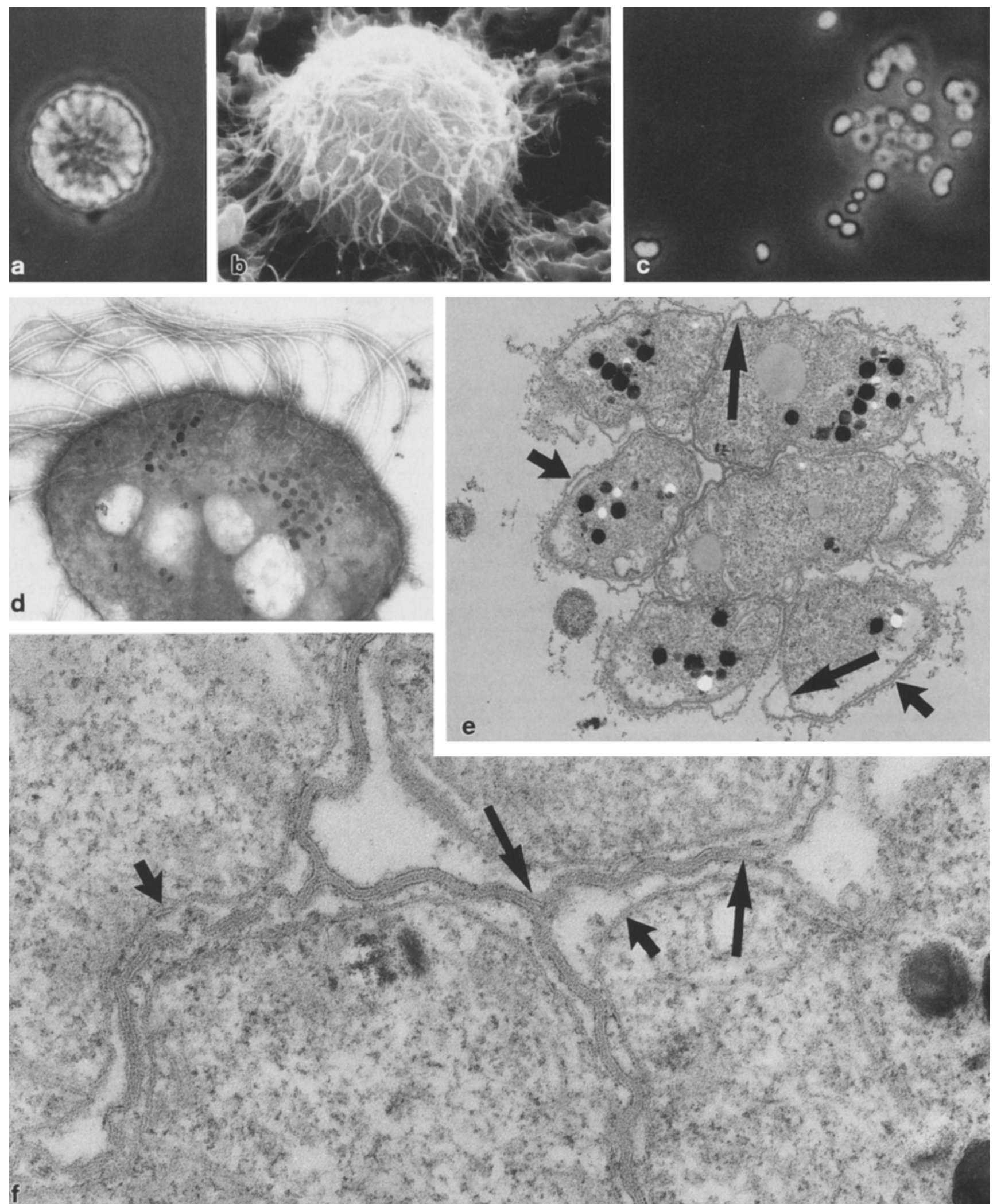

Fig. 1 a-f 
scope HB 5 scanning transmission electron microxcope fitted with a field emission electron source.

Magnetotoxis. The permanent magnetic dipole moment of each 5 intact organisms was estimated by measuring the average bacterial migration rates in the presence of applied magnetic fields ranging from 0.7 to 5.8 gauss and fitting the data to a Langevin function (Kalmijn 1981). The effect of a demagenetization procedure on swimming bacteria was evaluated using a commercial $60 \mathrm{~Hz} \mathrm{AC}$ degausser with peak fields of several hundred gauss.

\section{Results and discussion}

\section{Motility and structure}

The aggregate organisms were spherical, approximately $12.5 \mu \mathrm{m}$ in diameter with a rosette or mulberry-like morphology (Fig. $1 \mathrm{a}, \mathrm{b}$ ). Smaller forms, 3 to $8 \mu \mathrm{m}$ in diameter, with similar morphology were also observed. The organism displayed a co-ordinated rolling or spinning motility with effective translational movement in the magnctic ficld direction. Swimming speeds as assessed on 35 of the multicellular organisms ranged from 67 to 175 (average 105) $\mu \mathrm{m} \cdot \mathrm{s}^{-1}$ in a uniform magnetic field of 0.7 gauss. At the edge of an uncovered water droplet these organisms made intermittent excursions in the reverse of the field dircetion for about 100 to $500 \mu \mathrm{m}$ at swimming speeds approximately twice the forward speed, then returned to the edge of the drop at normal forward speed. The significance of this "ping-pong" motion, apparently peculiar to this organism, is unclear. Organisms trapped at the water-air interface were observed to rotate rapidly without translation. In open water droplets the organisms rapidly became non-motile. Exposure of the intact aggregate organisms to low osmotic pressure using distilled water caused a loss of motility and eventual disruption into clusters of unattached non-motile cells (Fig. 1c). These consisted of 10 to 30 roughly ovoid cells cach approximately 0.8 to $1.4 \mu \mathrm{m}$ in length and 0.6 to $0.8 \mu \mathrm{m}$ in width. Restoration of the original osmolarity did not restore aggregate structure or cell motility.

On rare occasions elliptical forms of the many-celled organism were seen in wet preparations by phase contrast microscopy. Whether this was a stage in microbial division remains to be determined. No convincing evidence was found of reproduction of this bacterial cell aggregate in these natural enrichments, either by optical or electron microscopy.

Fig. 1a-f. Optical and electron micrographs of the multicellular magnetotactic prokaryote. a Phase contrast photomicrograph of an intact organism in a wet preparation. Note rosette-like appearance of many-celled prokaryote $(\times 1700)$; b Scanning electron micrograph showing the distribution of flagella on the outer surfaces of the spherical shaped organisms within the many-celled prokaryote. $(\times 10,600)$; $c$ Phase contrast photomicrograph of a many-celled organism osmotically disrupted. Note individual cells with wide size distribution $(\times 1,500)$; $d$ Electron micrograph of a negatively stained individual cell of the many-celled prokaryote. Note asymmetric distribution of flagella. Magnetosomes and electron-lucent vacuoles
Flagella on the organism were of the unsheathed prokaryotic-lype, each $21.5 \mathrm{~nm}$ in diameter and located on the outer free surfaces of consticuent cells (Fig. $1 \mathrm{~d}$ ). Forward thrust necessary for translation of the organism could have been provided by formation of a llagellar bundle or bundles, or by flagellar rotation in one or a few selected cells. The excursions opposite to the imposed constant (DC) magnetic field direction after collision with the edge of the water droplet could have been a tactic response in which the organism reversed the direction of flagellar rotation for a short time. If a flagellar bundle was involved, such reversed rotation might be expected to cause a flagellar bundle to fly apart with loss of translational movement, contrary to the behavior observed by phase contrast microscopy. If several constituent cells were responsible for motility of the organism, reversal of the swimming direction could have involved co-ordination or communication between them.

In thin-section, each cell in the aggregate was structurally prokaryotic and Gram-negative in nature. Fach possessed cytoplasm rich in dispersed ribosomes with a fine skein of nuclear filaments, elcctron dense particles and granules with the appearance of poly- $\beta$-hydroxybutyrate (PHB) (Fig. 1e). Thesc granules appeared black on staining for light microscopy with Sudan Black B. The bacterial cytoplasm was limited by a plasma membrane with an outer membrane enclosing a periplasm with little evidence of peptidoglycan. The cell outer membranes were tightly apposed at the interior of each of the organisms (Fig. 1f). The apparent lack of rigidity of the murein layer in each cell would facilitate this process. These morphologically distinct, closcly associated membrane regions had the appearance of membrane junctions, each of which were uniformly $2 \mathrm{~nm}$ in width and appeared to hold the individual prokaryotic cells together. It is possible that this tigh apposition of membranes at these specialized junctions also allows intercell communication and could explain how individual cells participate in the coordinated motility observed for the entire organism.

Individual cells contained from 2 to 65 (average 31) electron dense particles occasionally arranged in rows. Each particle was irregular in shape and 85 to $90 \mathrm{~nm}$ in diameter. Those in parallel arrays were scparated by an envelope and from adjacent particles by an amorphous region of 8 to $10 \mathrm{~nm}$. $X$-ray mapping by energy dispersive elemental analysis showed that the bulk of the cell iron was located within these parlicles. Each particle contained a crystalline center of triangular or cuboidal outline

resembling poly- $\beta$-hydroxybutyrate (PHB) granules are evident. $(\times 25,000) ; \mathrm{e}$ Thin-section of aggregate organism illustrating Gramnegative prokaryotic nature of cach constituent cell. Note outer membranes (short arrows) and, cyloplasmic membranes (long arrows). $(\times 30,000)$; $f$ Higher magnification of contact regions between cells within the many-celled aggregate. Typical Gram-negative type cytoplasmic membranes (short arrows) are evident. Note points at which juxtaposed intercellular outer membranes have fused at regions hawing a constant $2 \mathrm{~nm}$ width (long arrows). The crystalline nature of the bacterial magnetosome and the amorphous material surrounding it is evident. $(x 111,600)$ 
measuring 40 to $45 \mathrm{~nm}$ in diameter in addition to a noncrystalline or amorphous halo 20 to $25 \mathrm{~mm}$ in width and of lower iron concentration. Elemental analysis and electron diffraction of the smaller multicellular organism (approximately $6 \mu \mathrm{m}$ in diameter) have shown that the crystalline particles consist of a mixture of the ferrimagnetic iron sulphide greigite, $\mathrm{Fe}_{3} \mathrm{~S}_{4}$, and the nonmagnetic iron sulphide pyrite, $\mathrm{FeS}_{2}$ (Mann et al. unpublished work). Thus, the magnelosomes of the present organism appear to differ in chemical composition from those of magnetite $\left(\mathrm{Fe}_{3} \mathrm{O}_{4}\right.$ )-containing bacteria (Frankel et al. 1979; Mann et al. 1984a, b; Matsuda el al. 1983).

\section{Magnetotaxis}

Magnetotaxis in bacleria is based on a permanent magnetic dipole moment with a fixed orientation in the cell (Frankel 1984). The measured permanent magnetic dipole moments of the aggregate organisms ranged from $5 \times 10^{-13}$ to $1 \times 10^{-12} \mathrm{ergs} \cdot$ Gauss $\mathrm{cm}^{-1}$ similar to those of other magnetotactic prokaryotes and sufficient for the magnetotactic response. The presence of ferrimagnetic greigite in the constituent cells would account for a permanent magnetic dipole moment in the organism.

Like unicellular magnetotactic bacteria (Blakemore et a1. 1980), the aggregate organisms were remagnetized by exposure to the $60 \mathrm{~Hz}$ AC magnetic field. Remagnetized organisms subsequently migrated opposite to the dircetion of a weak (several gauss) DC magnetic field. Remagnetization implied that there was an axis of motility in the intact organism and hence the projection of the net magnetic dipole moment could be forward or reverse with respect to the direction of thrust (Frankel 1984). However, unlike the unicellular magnetotactic bacteria (Blakcmorc et al. 1980), some aggregate organisms were demagnetized, subsequently failed to respond to changes in the direction of the weak DC field, and swam in seemingly random directions. Demagnetization of some organisms was consistent with relatively weak coupling of the magnetic dipole moments of the constituent cells in the intact organism; the demagnetization procedure probably left the constituent cells with permanent magnetic dipole moments, but reduced the vector sum of those moments to zero for the intact organism.

\section{Conclusions}

The magnetotactic aggregate organism studied here is morphologically similar to those collected in Brazil by Farina et al. 1983. However, intercellular connections like those in the present organism were not reported. Other prokaryotes known to exist as motile, multicellular aggregates include the myxobacteria and photosynthetic consortia. The former are unicellular gliding bacteria which aggregate to form fruiting bodies but with swarmer cells retaining their individuality throughout the process of cooperative morphogenesis. Photosynthetie consortia such as "Chlorochromatium" or "Pelochromatium" consist of dissimilar cells of several species and are not known to form specialized membrane adhesions. Intercellular connections have been reported in certain cyanobacteria (Lang and Fay 1971) but these do not entail structures similar to those described here. As the eells comprising the present aggregate organisms are of the Gram-negative type, the closely apposed membranes involved are, by definition, outer bacterial membranes and not cytoplasmic membranes. Thus, these many-celled prokaryotes are like no other known organisms. The intercellular connections described here could be functionally important in the motility and magnetotaxis of the aggregate organisms, perhaps by coordinating flagellar activity among the constituent cells.

In eukaryotes, multicellularity refers to cell specialization and cooperation in a many-celled organism. While in prokaryotes, multicellularity has heen iess clearly defined, three requirements have been proposed (Starr and Schmidt, 1981): (a) the organism be many-celled, (b) the cells have a permanent and characteristic juxtaposition, and (c) the cells exhibit discernable distinction in structure or function. The organism reported here clearly satisfies the first two criteria. While no evidence has been found for cellular distinction in structure or function to support the final criterion, it may be argued that the complex motility exbibited by the intact aggregate but never by the individual cells alone, implies coordination of flageltar activity and communication between individual cells. Moreover, the asymmetrical arrangement of flagella on each constituent cell may reflect a spatial distribution required for coordinated motility. We propose that the magnetotactic aggregate is a multicellular prokaryote.

However, definitions of multicellularity aside, the close apposition of the outer individual cell membranes in the intact organism is unique among prokaryotes. Furthermore, they provide the first example, in an extant prokaryotic species, of a lundamental morphological trait expressed among multicellular eukaryotes; that of intercellular membrane adhesions ultrastructurally similar in appearance to eukaryotic cell junctions. They provide evidence that mulicellularity involving specialized intercellular membranc junction-like structures in prokaryoles may have preceded that in eukaryotes.

Acknonledgements. We gratefully acknowledge the help of A. Garratt-Reed, and discussions with $H$. Lins de Barros, D. Esquivel, J. Danon and J. Waterbury. F. G. R. and C. R. Were partially supported by the University of New Hampshire Research Office; R. P. B.. N. A. B., D. M. and R. B. F. by the Office of Naval Research, and R. P. B., D. A. B. and R. B. F. by the National Science Foundation.

\section{References}

Blakemore RP (1975) Magnetotactic bacteria. Science 190:377379

Blakemore RP (1982) Magnetolactic bacteria. Annu Rev Microbiol $36: 217-238$

Blakemore RP, Frankel RB, Kalmijn AJ (1980) South-seeking magnetotactic bacteria in the southern hemisphere. Nature $286: 384-385$

Blakemorc RP, Blakemorc NA, Bazylnnski DA, Moench TT (1989) Magnclutatic bacteria. In: Staky JT, Bryant EP, Pfennig N, 
Holt JG (eds) Bergey's Manual of systematic bacteriology, vol. 3. Williams and Wilkins. Baltimore, pp 188?-1888

Farina M, Lins de Barros H, Motta de Esquivel D, Danon J (1983) Ultrastructure of a magnetotaclic microorganism. Biol Call $48: 85-88$

Frankel RB (1984) Magnetic guidanee of organisms. Annu Rev Biophys Bioeng 13:85-103

Frankel RB, Blakemore RP. Wolfe RS (1979) Magnetite in freshwater magnetotactic bacteria. Science 203:1355-1356

Kalmijn AJ (1981) Biophysics of geomagnetic field detection. IFFF, Trans Magnetics MAG-17:1113-1124

Lang N.J, Fay P (1971) The heterocysts of blue-green algae. II. Details of ultrastructure. Proc R Soc Lond B 178:193-203

Mann S, Frankel RB, Blakemore RP (1984a) Structure, morphology and crystal gtowth of bacterial magnetite. Nature 310:405-407

Mann S, Moench TT, Williams RJP (1984b) A high resolution electron microscopic investigation of bacterial magnetic. Implications for crystal growth. Proc R Soc Lond B 221:385-393
Malsuda T, Endo I, Osakabe N, Tonomura A (1983) Morphology and structurc of biogenic magnetite particles. Nature 302: $411-$ 412

Moench TT, Konctka WA (1978) A novel method for the isolation and study of a magnetotactic bacterium. Arch Microbiol $119 ; 203-212$

Rodgers FG (1979) L11rastructure of Legionello pneumophila. J Clin Pathol 32:1195-1202

Rodgers FG, Davey MR (1982) Ultrastructure of the cell envelope layers and surface details of Legionello pneumohila. I Gen Microbiol 128:1547-1557

Starr MP, Schmidt JM (1981) Prokaryote diversily. In: Starr MP, Stolp $\mathrm{H}_{3}$ Trüper IIG, Balows A, Schlegel HG (cds) The prokaryotes: A handbook on habitats, isolation, and identification of bacteria. Springer. Berlin IIeidelberg New York, chap 1. pp $3-42$

Stookey LL (1970) Ferrozine - a new spectropholometric reagent for iron. Anal Chem 42:779-781 